\title{
The impact of remifentanil on incidence and severity of postoperative nausea and vomiting in a university hospital-based ambulatory surgery center: a retrospective observation study
}

\author{
Risa Hara ${ }^{1}$, Kiichi Hirota ${ }^{1,2}$, Masami Sato ${ }^{1}$, Hiroko Tanabe ${ }^{1}$, Tomoko Yazawa ${ }^{1}$, Toshie Habara ${ }^{1}$, and \\ Kazuhiko Fukuda ${ }^{1}$ \\ ${ }^{1}$ Department of Anesthesia and ${ }^{2}$ Day Surgery Unit, Kyoto University Hospital, Kyoto, Japan
}

Background: Ambulatory surgery, including short-stay surgery, has become a common choice in clinical practice. For the success of ambulatory surgery, perioperative care with safe and effective anesthesia and postoperative analgesia, which can reduce the occurrence of postoperative nausea and vomiting (PONV), is essential. The effect of remifentanil on the occurrence and severity of PONV has not been thoroughly examined, particularly, in an ambulatory surgery setting. Here, we investigate whether remifentanil influences the occurrence and severity of PONV in a university hospital-based ambulatory unit.

Methods: We retrospectively analyzed a total of 1,765 cases of patients who had undergone general anesthesia at our ambulatory surgery unit. Parameters, such as occurrence and severity of nausea, vomiting or retching, use of antiemetic drugs, amount of postoperative analgesic and patient satisfaction, were extracted from the records and analyzed between the groups that received and not received remifentanil.

Results: Within 565 patients of the RF group, 39 patients (6.6\%) experienced nausea, 7 patients (1.2\%) experienced vomiting or retching, and 10 patients (1.8\%) were given antiemetic; in addition, the maximum VAS value for nausea was $12.1 \mathrm{~mm}$. In 1,200 patients of the non RF group, 102 patients (8.5\%) experienced nausea, 19 patients (1.6\%) experienced vomiting or retching, and 34 patients $(2.8 \%)$ were given antiemetic, and the maximum VAS value was $13.2 \mathrm{~mm}$. There were no statistically significant differences between the two groups.

Conclusions: Our results indicate that remifentanil did not increase the occurrence of PONV in patients within the ambulatory surgery unit. (Korean J Anesthesiol 2013; 65: 142-146)

Key Words: Ambulatory surgery, Postoperative nausea and vomiting, Remifentanil.

Received: September 19, 2012. Revised: 1st, January 9, 2013; 2nd, January 25, 2013. Accepted: January 30, 2013.

Corresponding author: Kiichi Hirota, M.D., Ph.D., Department of Anesthesia, Kyoto University Hospital, 54 Shogoin-Kawaharacho, Sakyo-Ku, Kyoto 606-8507, Japan. Tel: 81-75-751-3433, Fax: 81-75-752-3259, E-mail: hif1@mac.com

(c) This is an open-access article distributed under the terms of the Creative Commons Attribution Non-Commercial License (http:// creativecommons.org/licenses/by-nc/3.0/), which permits unrestricted non-commercial use, distribution, and reproduction in any medium, provided the original work is properly cited. 


\section{Introduction}

Ambulatory surgery has many merits compared to that of conventional surgery performed at the hospital. Such merits include the following; increased number of annual surgical cases, decrease in the number of patients on the surgical-wait list, and reduction in hospital costs. Although ambulatory surgery is becoming useful and common, factors that can lead to its failure, including ineffective postoperative analgesia, postoperative drowsiness, and postoperative nausea and vomiting (PONV), have not been completely conquered $[1,2]$. A recent large sample-size study reported that postoperative nausea is observed in at least one of five patients [3-6]. Persistent PONV may result in the following; dehydration, electrolyte imbalance, tension on suture lines, venous hypertension, and pulmonary aspiration of the vomitus. For ambulatory surgery to succeed, these causes of failure must be correctly recognized. It is essential to have an anesthetic procedure that mitigates these factors [1].

Remifentanil is known for its intense analgesic effect along with a rapid onset and very short duration of action, thus making it a safe and useful drug. However, whether remifentanil induces the onset or worsens PONV has not been thoroughly examined [7], particularly, in patients undergoing ambulatory surgery. Therefore, we retrospectively studied and analyzed anesthetic records of patients that underwent general anesthesia to verify the effects of remifentanil on PONV in a university hospital-based ambulatory unit.

\section{Materials and Methods}

This was a retrospective observation analysis for all consecutive adult outpatients ( $>15$-year-old) who were managed under general anesthesia, from February 1, 2007 to October 31, 2009, at the day surgery unit (DSU) of Kyoto University Hospital. A written informed consent for data collection was preoperatively obtained from each of the patients. Exclusion criteria were as follows: all cases without the $100 \mathrm{~mm}$ visual analog scale (VAS) or verbal numerical rating scale (VNRS) for nausea within $24 \mathrm{~h}$ after the operation by any reasons $[2,8]$. All the case that met the exclusion criteria were excluded from further analysis. The primary objective was to determine the effects of remifentanil on the incidence and severity of PONV, as well as administration of antiemetics over $24 \mathrm{~h}$ postoperatively. Second goal was to determine the frequency of use of analgesics and patient satisfaction. Patients were classified into two groups; those receiving remifentanil (RF group) or not (non RF group) during anesthesia.

\section{Perioperative care protocol}

All the patients were admitted to the DSU on the day of surgery. The preoperative fasting periods for solid food and clear fluids were at least $6 \mathrm{~h}$ and $2 \mathrm{~h}$, respectively. No patient was premedicated and the methods of general anesthesia, including airway management and usage of drugs, including remifentanil or fentanyl as opioids and sevoflurane, propofol, or midazolam as hypnotics and sedatives, were dependent on the responsible anesthesiologists. Local infiltration anesthesia and use of nonsteroidal anti-inflammatory drugs (NSAIDs) were encouraged during surgery. Peripheral nerve blocks, such as femoral nerve block, sciatic nerve block, brachial plexus nerve block, transversus abdominis plane block, paravertebral block, and ankle block, were administered in appropriate cases. Nitrous oxide was not used at all. Neither gastric tube nor urinary catheter was placed. No prophylactic antiemetics, such as metoclopramide, dexamethasone, or droperidol, were administered pre- or intraoperatively. Strabismus surgery, laparotomy, thoracotomy, laparoscopic surgery, or thoracoscopic surgery were not performed. Breast surgery, gynecological surgery, including hysteroscopy, and cervical conization of uterus, laryngeal and thyroid surgery, knee and shoulder arthroscopic surgery, plastic surgeries, biopsy of prostate, transurethral resection of the bladder tumor, and other minor surgeries were performed. After surgery, patients were transported first to the postanesthesia care unit (PACU), and then to the stepdown recovery area (SRA) in the DSU. Patients were allowed to take fluids and a light meal if they desired. In the PACU and SRA, trained nursing staffs, who were blinded to the group allocation, interviewed the patients and documented adverse events, including nausea and vomiting or retching, and routinely recorded vital signs every 15-30 min. The drugs administered were noted. The attending anesthesiologists administrated antiemetic (metoclopramide $10 \mathrm{mg}$ IV or droperidol $0.5-1.0 \mathrm{mg}$ IV) drugs as per their discretion.

\section{Measurements}

Episodes of PONV were the primary outcomes of this study, which were accounted for, by at least one obvious emetic episode (vomiting or retching) within $24 \mathrm{~h}$ after surgery or a score of over $10 \mathrm{~mm}$ on the $100 \mathrm{~mm}$ VAS ( $0 \mathrm{~mm}$, no symptom; $100 \mathrm{~mm}$, the worst symptom imaginable) or over 1 on the VNRS ( 0 , no symptom; 10, the worst symptom imaginable), or both [9]. An evaluation with the $100 \mathrm{~mm}$ VAS was performed postoperatively at $30 \mathrm{~min}, 1 \mathrm{~h}, 2 \mathrm{~h}$, and upon leaving the recovery room, and in the morning on the day after surgery. The use of the antiemetics, fentanyl and NSAIDs in the PACU and SRA, as well as patient satisfaction was also recorded. Trained DSU nurses directly interviewed each patient on the 'morning after surgery in a telephone call or by meeting the patient directly. Patients were asked about symptoms after DSU discharge with the VNRS, 
including PONV and the pain VAS, and the patients provided a score for satisfaction with the surgical operation and anesthesia procedure $[2,8]$.

\section{Statistical analysis}

Demographic data, such as age, body weight, height, body mass index (BMI), and duration of anesthesia and surgery were compared using unpaired Student's t-test. The incidence of PONV was analyzed with the Fisher's exact test. All values were expressed as the mean ( \pm Standard deviation [SD]) or as \% (number). $\mathrm{P}$ values $<0.05$ were considered significant.

Table 1. Demographic Characteristics

\begin{tabular}{lccc}
\hline \multicolumn{1}{c}{ Set } & $\begin{array}{c}\text { RF group } \\
(\mathrm{n}=565)\end{array}$ & $\begin{array}{c}\text { Non RF group } \\
(\mathrm{n}=1200)\end{array}$ & P value \\
\hline Sex (M/F) & $158 / 427$ & $306 / 894$ & 0.49 \\
Age $(\mathrm{yr})$ & $48.7 \pm 17.9$ & $50.0 \pm 17.4$ & 0.17 \\
Height $(\mathrm{cm})$ & $160.3 \pm 8.7$ & $159.2 \pm 8.4$ & 0.14 \\
Weight $(\mathrm{kg})$ & $57.2 \pm 11.1$ & $56.9 \pm 12.3$ & 0.66 \\
BMI $\left(\mathrm{kg} / \mathrm{m}^{2}\right)$ & $22.2 \pm 3.5$ & $22.4 \pm 4.0$ & 0.23 \\
History of smoking (n) & $19.7 \%(111)$ & $20.9 \%(251)$ & 0.57 \\
History of PONV (n) & $6.9 \%(39)$ & $8.9 \%(107)$ & 0.17 \\
History of motion sickness (n) & $29.3 \%(166)$ & $26.1 \%(313)$ & 0.15 \\
Intraoperative sevoflurane use & $12.6 \%(74)$ & $62.3 \%(748)$ & $<0.001$ \\
Intraoperative fentanyl use & $1.9 \%(11)$ & $2.3 \%(28)$ & 0.72 \\
Duration of anesthesia (min) & $128.4 \pm 59.2$ & $94.1 \pm 55.9$ & $<0.001$ \\
Duration of surgery (min) & $84.2 \pm 53.6$ & $57.8 \pm 44.3$ & $<0.001$ \\
\hline
\end{tabular}

Values are mean \pm SD or \% (number). RF group was received remifentanil, non RF group was not received during anesthesia. PONV: postoperative nausea and vomiting.

Table 2. Types and Number of Surgery Performed

\begin{tabular}{lcc}
\hline & $\begin{array}{c}\text { RF group } \\
(\mathrm{n}=565)\end{array}$ & $\begin{array}{c}\text { Non-RF group } \\
(\mathrm{n}=1200)\end{array}$ \\
\hline Breast surgery & 97 & 254 \\
Hysteroscopy & 110 & 190 \\
Cervical conization of uterus & 33 & 72 \\
Laryngeal surgery & 24 & 68 \\
Thyroid surgery & 14 & 52 \\
Maxillary sinus surgery & 36 & 59 \\
Knee surgery & 33 & 67 \\
Shoulder surgery & 26 & 34 \\
Digit surgery & 28 & 52 \\
Ankle surgery & 21 & 61 \\
Plastic surgeries & 32 & 52 \\
Prostate biopsy & 58 & 92 \\
TUR-Bt & 21 & 35 \\
Other minor surgeries & 32 & 112
\end{tabular}

Values are number of each surgery. RF group was received remifentanil, non RF group was not received during anesthesia. TUR-Bt: transurethral resection of the bladder tumor.

\section{Results}

Patients were studied retrospectively from February 1, 2007 to October 31, 2009 at the DSU of Kyoto University Hospital. Only those patients who underwent general anesthesia were included in the study. A total of 3,456 case records were studied. Those who met the exclusion criteria were excluded. A total of 1691 cases (48.9\%) were excluded, leaving 1,765 cases available for the analysis. The population characteristics are summarized in Table 1 . Of the 1,765 cases studied, $75.2 \%$ were women, $79.9 \%$ were non-smokers, $8.3 \%$ had a history of PONV, and $27.2 \%$ had a history of motion sickness. Operations performed were indicated as Table 2. The RF group consisted of 565 patients and the non RF group consisted of 1,200 patients. No significant differences with regard to patient demographics, such as gender, age, height, body weight, BMI, and intraoperative use of fentanyl, were observed between the two groups (Table 1). Significant differences were observed between the groups with regard to the use of sevoflurane, anesthesia time, and operation time (Table 1).

Overall, 141 of 1,756 cases (8.0\%) had PONV, 26 cases (1.5\%) developed vomiting or retching, and antiemetics were administrated to 44 patients (2.5\%) (Table 3 ). The maximum VAS score for nausea were $12.1 \mathrm{~mm}$ in the RF group and $13.2 \mathrm{~mm}$ in the non RF group; however, no significant differences were observed

Table 3. Incidence of Postoperative Nausea and Vomiting (PONV) and Severity of Nausea

\begin{tabular}{llll}
\hline & $\begin{array}{c}\text { RF group } \\
(\mathrm{n}=565)\end{array}$ & $\begin{array}{c}\text { Non-RF group } \\
(\mathrm{n}=1200)\end{array}$ & P value \\
\hline Nausea (VAS > 30 mm or VNRS* $>3)$ & $6.6 \%(39)$ & $8.5 \%(102)$ & 0.26 \\
Vomiting and retching & $1.2 \%(7)$ & $1.6 \%(19)$ & 0.68 \\
Post operational use of antiemetics & $1.8 \%(10)$ & $2.8 \%(34)$ & 0.20 \\
Nausea : maximum VAS value $(\mathrm{mm})$ & $12.1 \pm 6.6$ & $13.2 \pm 7.6$ & 0.31 \\
\hline
\end{tabular}

Values are mean \pm SD or $\%$ (number). RF group was received remifentanil, non RF group was not received during anesthesia. VAS: visual analogue scale, VNRS: verbal numerical rating scale. ${ }^{*} 0$ : no symptom, 10: the worst symptom imaginable. NSAIDS: nonsteroidal anti-inflammatory drugs.

Table 4. Incidence of the Postoperative Use of Analgesics and Score of Patient Satisfaction

\begin{tabular}{lccc}
\hline & $\begin{array}{r}\text { RF group } \\
(\mathrm{n}=565)\end{array}$ & $\begin{array}{c}\text { Non-RF group } \\
(\mathrm{n}=1200)\end{array}$ & P value \\
\hline Post operational use of NSAIDS & $10.1 \%(57)$ & $11.3 \%(136)$ & 0.46 \\
Post operational use of fentanyl & $3 \%(17)$ & $2.3 \%(28)$ & 0.42 \\
Patient satisfaction* & 9.7 & 9.7 & 0.61 \\
\hline
\end{tabular}

Values are \% (number). RF group was received remifentanil, non RF group was not received during anesthesia. NSAIDS: nonsteroidal antiinflammatory drugs. *Global satisfaction with the surgical procedure and anesthesia care; score 0 : very dissatisfied, score 10 : very satisfied. 
Table 5. Comparison between the RF and Non-RF Groups in Patients with Postoperative Nausea and Vomiting (PONV)

\begin{tabular}{lccc}
\hline & $\begin{array}{c}\text { RF group } \\
(\mathrm{n}=46)\end{array}$ & $\begin{array}{c}\text { Non RF group } \\
(\mathrm{n}=121)\end{array}$ & P value \\
\hline Sex $(\mathrm{M} / \mathrm{F})$ & $18 / 28$ & $27 / 94$ & 0.03 \\
Age $(\mathrm{yr})$ & $46.2 \pm 17.9$ & $44.6 \pm 19.0$ & 0.61 \\
Height $(\mathrm{cm})$ & $161.5 \pm 11.1$ & $158.9 \pm 8.5$ & 0.10 \\
Weight $(\mathrm{kg})$ & $59.2 \pm 10.8$ & $55.5 \pm 8.5$ & 0.06 \\
BMI $\left(\mathrm{kg} / \mathrm{m}^{2}\right)$ & $22.8 \pm 3.3$ & $21.9 \pm 3.7$ & 0.21 \\
Duration of anesthesia $(\mathrm{min})$ & $154.4 \pm 74.0$ & $135.9 \pm 61.6$ & 0.10 \\
Duration of surgery (min) & $104.8 \pm 65.6$ & $92.0 \pm 52.8$ & 0.19 \\
Nausea: Maximum VAS value $(\mathrm{mm})$ & $37.4 \pm 26.9$ & $35.2 \pm 26.0$ & 0.82 \\
Patient satisfaction* & $9.1 \pm 0.64$ & $9.4 \pm 0.26$ & 0.78
\end{tabular}

Values are mean \pm SD or number (\%) or mean \pm SD. VAS: $100 \mathrm{~mm}$ visual analogue scale. *Global satisfaction with the surgical procedure and anesthesia care; score 0 : very dissatisfied, score 10: very satisfied.

between the RF and non RF groups (Table 3). Furthermore, it was observed that there were no differences between the groups for postoperative use of fentanyl and NSAIDs and patient satisfaction (Table 4). Afterwards, a comparison was done between the RF and non RF groups in patients who experienced PONV (Table 5). There were no differences observed between the groups for the parameters analyzed.

Next, we examined the influence of sevoflurane on PONV in this study. Number of cases which had nausea, vomiting or retching, and postoperative use of antiemetics were 87,15 , and 13 , respectively, in the non sevoflurane group $(\mathrm{n}=943)$. On the other hand, those of the sevoflurane group $(\mathrm{n}=822)$ were 54 , 11 , and 21 , respectively. There were no statistical differences between the groups.

\section{Discussion}

Our primary objective of the present study was to determine the incidence of PONV and outcome of the use of antiemetics over $24 \mathrm{~h}$ postoperatively. No significant difference was observed between the RF and non RF groups for the occurrence and severity of nausea and vomiting or the use of antiemetic drugs.

It is reported that PONV occurs in $20-30 \%$ of the general surgical population $[5,6]$. The incidence of PONV during the first 24 postoperative hours in the present study was very low compared to that of the previous reports, although the patients were not administrated with antiemetics for prophylactic purpose. In the present study, the mean duration of anesthesia was less than $3 \mathrm{~h}$, and the frequency of fentanly use was less than $3 \%$. These factors are thought to contribute to the low basal incidence of PONV in this study.

Apfel et al. [6] defined the use of opioids as one of the four major risk factors for the occurrence of PONV. In fact, it is reported that the use of fentanyl in an ambulatory surgery setting increases PONV and delays post anesthesia recovery [2]. Because the opioid remifentanil is known for its extremely short half-life [10], it is reasonable to assume that its use would be associated with reduced opioid-related side-effects, such as PONV. However, a recent meta-analysis demonstrated that remifentanil is associated with a faster recovery from anesthesia and more frequent postoperative analgesic requirement with no overall impact on PONV compared to opioids, such as fentanyl, alfentanil, or sufentanil used in general anesthesia, and that it is concluded that remifentanil does not seem to offer any advantage for lengthy, major interventions, but may be useful for selected patients [7]. We demonstrated that the use of remifentanil does not exacerbate the incidence and severity of PONV, nor does it facilitate postoperative analgesic requirement in an ambulatory anesthesia setting. This is different from the result of the meta-analysis, which compares the impact of remifentanil to that of longer-acting opioids, such as fentanyl, alfentanil, or sufentanil [7]. The disadvantage of opioid-free anesthesia could be intraoperative instability to surgical insults. In fact, it was observed that administration of remifentanil reduced body movement of patietns in response to surgical manipulation in this study (data not shown). A peripheral nerve block and infiltration of local anesthesia were performed in patients along with general anesthesia. Use of NSAIDs was also encouraged along with anesthesia. Combined with the effective and reasonable pain management, good control of postoperative analgesia can be achieved with remifentanil in the ambulatory surgery setting, even though it is an ultra short-acting opioid agonist [11].

One of the weak points of this study is that there are significant differences in intraoperative sevoflurane use between the RF and non RF groups. The rate of sevoflurane usage was lower in the RF group compared to the non RF group (Table 1). Because sevoflurane is reported to induce PONV and propofol is reported to reduce PONV [1,2], theoretically, there was a possibility that sevoflurane induced PONV in the non RF group or that propofol used in the non-sevoflurane group prevented PONV in the RF group. However, our subanalysis demonstrated that use of sevoflurane did not affect the incidence of PONV or usage of antiemetics at least statistically significantly, as described in the result section. Thus, choice of anesthetics does not affect the incidence or severity of PONV under the use of remifentanil at least in this study. The other point is the discrepancy of durations of anesthesia and surgery. However, results in Table 5 demonstrates that there are no significant difference of duration of either anesthesia or surgery in patients with PONV. Thus, duration of either anesthesia or surgery might not affect the incident of PONV in this study.

In conclusion, remifentanil does not increase the frequency of PONV or the use of postoperative analgesics in an ambula- 
tory surgery setting. Thus, remifentanil is a safe and beneficial drug with regard to the occurrence and severity of PONV for ambulatory anesthesia.

\section{Acknowledgments}

We are grateful to Dr. Tomoharu Tanaka at Kyoto University Hospital for useful discussions.

\section{References}

1. Shirakami G, Teratani Y, Namba T, Hirakata H, Tazuke-Nishimura M, Fukuda K. Delayed discharge and acceptability of ambulatory surgery in adult outpatients receiving general anesthesia. J Anesth 2005; 19: 93-101.

2. Shirakami G, Teratani Y, Segawa H, Matsuura S, Shichino T, Fukuda K. Omission of fentanyl during sevoflurane anesthesia decreases the incidences of postoperative nausea and vomiting and accelerates postanesthesia recovery in major breast cancer surgery. J Anesth 2006; 20: 188-95.

3. Koivuranta M, Laara E, Snare L, Alahuhta S. A survey of postoperative nausea and vomiting. Anaesthesia 1997; 52: 443-9.

4. Gan TJ, Meyer T, Apfel CC, Chung F, Davis PJ, Eubanks S, et al. Consensus guidelines for managing postoperative nausea and vomiting. Anesth Analg 2003; 97: 62-71.

5. Gan TJ, Meyer TA, Apfel CC, Chung F, Davis PJ, Habib AS, et al. Society for Ambulatory Anesthesia guidelines for the management of postoperative nausea and vomiting. Anesth Analg 2007; 105: 1615-28.

6. Apfel CC, Korttila K, Abdalla M, Kerger H, Turan A, Vedder I, et al. A factorial trial of six interventions for the prevention of postoperative nausea and vomiting. N Engl J Med 2004; 350: 2441-51.

7. Komatsu R, Turan AM, Orhan-Sungur M, McGuire J, Radke OC, Apfel CC. Remifentanil for general anaesthesia: a systematic review. Anaesthesia 2007; 62: 1266-80.

8. Sato M, Shirakami G, Tazuke-Nishimura M, Matsuura S, Tanimoto K, Fukuda K. Effect of single-dose dexmedetomidine on emergence agitation and recovery profiles after sevoflurane anesthesia in pediatric ambulatory surgery. J Anesth 2010; 24: 675-82.

9. Apfel CC, Roewer N, Korttila K. How to study postoperative nausea and vomiting. Acta Anaesthesiol Scand 2002; 46: 921-8.

10. Minto CF, Schnider TW, Shafer SL. Pharmacokinetics and pharmacodynamics of remifentanil. II. Model application. Anesthesiology 1997; 86: 24-33.

11. Kapila A, Glass PS, Jacobs JR, Muir KT, Hermann DJ, Shiraishi M, et al. Measured context-sensitive half-times of remifentanil and alfentanil. Anesthesiology 1995; 83: 968-75. 